Federal Reserve Bank of Minneapolis

Research Department Staff Report 338

Revised December 2004

\title{
Comment on Gali and Rabanal's "Technology Shocks and Aggregate Fluctuations: How Well Does the RBC Model Fit Postwar U.S. Data?"*
}

\author{
Ellen R. McGrattan \\ Federal Reserve Bank of Minneapolis \\ and University of Minnesota
}

\begin{abstract}
Gali and Rabanal provide statistical evidence that, in their view, puts into question the real businesscycle paradigm in favor of the sticky-price paradigm. I demonstrate that their statistical procedure is easily misled in that they would reach the same conclusions even if their data had been simulated from an RBC model. I also demonstrate that sticky-price models do a poor job generating U.S.-like business cycles with only shocks to technology, the federal funds rate, and government consumption. This explains why Gali and Rabanal need large unobserved shocks to preferences and to the degree of monopoly power.
\end{abstract}

*This discussion was prepared for the 2004 NBER Macroeconomics Annual. I received very helpful comments from my colleagues at the Federal Reserve Bank of Minneapolis. Data, codes, and notes used in this project are available at my website (minneapolisfed.org/research). The views expressed herein are those of the author and not necessarily those of the Federal Reserve Bank of Minneapolis or the Federal Reserve System. 


\section{Introduction}

An important task of macroeconomists is the development of models that account for specific features of the business cycle. All policymakers would agree that having reliable models to analyze the effects of policy is useful. In taking on the important endeavor of developing reliable models, I applaud Gali and Rabanal (GR hereafter). I do, however, dispute some of their key findings.

GR survey research in the structural vector autoregression (SVAR) literature emphasizing the role of technology for the business cycle. (See the many references in GR's Section 2.2.) The findings of this literature are used to dismiss a line of business-cycle research beginning with Kydland and Prescott's (1982) "real business cycle" (RBC) model. The claim is that the data clearly show that RBC models are inconsistent in crucial ways with the observed behavior of the United States economy in the postwar period. This claim amounts to asserting that no RBC model can produce time series for key macro aggregates - namely productivity and hours - that have similar patterns to those in U.S. data. The SVAR literature arrives at this claim by estimating empirical impulse responses and noting that the responses are different from the theoretical impulse responses in most RBC models.

In these comments, I argue that the claim of the SVAR literature is incorrect. I do this by estimating a standard RBC model with maximum likelihood for U.S. data. My estimation procedure ensures that the model can account for the patterns of productivity and hours in the data. With this RBC model, I then show that the SVAR procedure is easily misled. I simulate time series for the model (many times), apply the SVAR procedure, and estimate empirical impulse responses. I show that these empirical impulse responses look very similar to those estimated in the literature. Thus, given data simulated from my model, the SVAR procedure would wrongly conclude that the data were not simulated from a real business cycle model.

The problem with trying to use the SVAR procedure to make broad claims about a class of models, like the entire class of RBC models, is the following: most RBC models do not satisfy the narrow set of identifying assumptions typically made in the SVAR literature. My estimated RBC model is no exception. Hence, the SVAR procedure is misspecified with respect to most of the models it tries to shed light on.

On this point, I think there is some agreement between Gali and Rabanal and myself. ${ }^{1}$

1 See "Addendum: A Response to Ellen McGrattan" where Gali and Rabanal note that "a misidentified 
The SVAR procedure is not useful for evaluating models or classes of models that do not satisfy the SVAR's precise identifying assumptions. I conclude from this that since we do not know the assumptions a priori, SVARs are not a useful guide to developing new models. Moreover, since we do not know the identifying assumptions a priori, the SVAR cannot robustly identify how the economy responds to shocks, like technology or monetary shocks. SVARs are potentially useful but only for classes of models which satisfy all of the identifying assumptions. In every application of which I am aware, the class of models that satisfy the explicit or implicit identifying assumptions of the SVAR procedure is an extremely small subset of the class of interesting models.

The false rejection of the RBC model motivates the second part of GR's study, a study of business cycles using a model with sticky prices. Unfortunately, like many other studies in the sticky-price literature, GR do not include investment in their model. I introduce investment into a version of their model and analyze its predictions for business cycles. I find that technology shocks, monetary shocks, and government consumption shocks are of little importance in the sticky-price model. This explains why GR find that preference shocks and shocks to the degree of monopoly power play such a large role for aggregate fluctuations.

\section{The Death Knell for RBC Theory}

Gali and Rabanal first review the SVAR literature that considers the fit of real business cycle models and the role of technology shocks for business cycles. They ask, How well does the RBC model fit postwar U.S. data? The answer they give is 'not so well.' According to evidence from the SVARs, hours fall in response to technology shocks and the contribution of technology shocks to the business cycle is small. In standard RBC models, the opposite is true. Francis and Ramey (2002), who have contributed to the SVAR literature that GR review, summarize the findings of this literature by saying that "the original technologydriven real business hypothesis does appear to be dead."

and/or misspecified SVAR often leads to incorrect inference. ... In those cases the finding of incorrect inference is neither surprising nor novel, since it restates points that have already been made in the literature." 


\subsection{Applying Blanchard-Quah}

Let me start by summarizing how researchers in the SVAR literature reach the conclusion that RBC theory is not consistent with U.S. data. It is a direct application of Blanchard and Quah (1989). They estimate a vector autoregression (VAR) using data on labor productivity and hours, invert it to get a moving average (MA) representation, and impose certain "structural" assumptions about the shocks hitting the economy. They then argue that the empirical impulse responses from the structural MA are very different from the theoretical impulse responses of a standard RBC model. Furthermore, they show that the contribution of technology shocks to output fluctuations is empirically small, a prediction at odds with standard RBC theories.

To be more precise, let $X_{t}$ be a two-dimensional vector containing the change in the $\log$ of labor productivity and the change in the log of hours. The first step is to estimate a vector autoregression by regressing $X_{t}$ on a certain number of lags. GR chose four. They invert this VAR to get the corresponding Wold moving average,

$$
X_{t}=v_{t}+B_{1} v_{t-1}+B_{2} v_{t-2}+\ldots
$$

where $v_{t}$ is the residual from the VAR and $E v_{t} v_{t}^{\prime}=\Omega$. Mechanically, it is easy to recursively compute the $B$ coefficients having estimates of the VAR coefficients. An estimate of the matrix $\Omega$ is easily constructed from the VAR residuals.

One more step is needed to derive the structural MA. The goal is to work with an MA process that has interpretable shocks, namely a shock they call a "technology" shock, and a shock they call a "demand" shock. In particular, the structural MA they use is

$$
X_{t}=C_{0} e_{t}+C_{1} e_{t-1}+C_{2} e_{t-2}+\ldots
$$

where $E e_{t} e_{t}^{\prime}=\Sigma, e_{t}=C_{0}^{-1} v_{t}$, and $C_{j}=B_{j} C_{0}$ for $j \geq 1$. The first element of $e_{t}$ is the technology shock and the second element is the demand shock.

We need identifying restrictions to determine the seven parameters in $C_{0}$ and $\Sigma$. Seven restrictions typically used in the SVAR literature that GR review are as follows. Three come from equating variance-covariance matrices $\left(C_{0} \Sigma C_{0}^{\prime}=\Omega\right)$. Three come from assuming that the shocks are orthogonal $(\Sigma=I)$. The last comes from the assumption that demand shocks have no long-run effect on labor productivity $\left(\sum_{j} C_{j}(1,2)=0\right)$.

With these restrictions imposed, I can compute the empirical impulse responses. Since I want to compare models to the national accounts, I am actually going to work, not with 


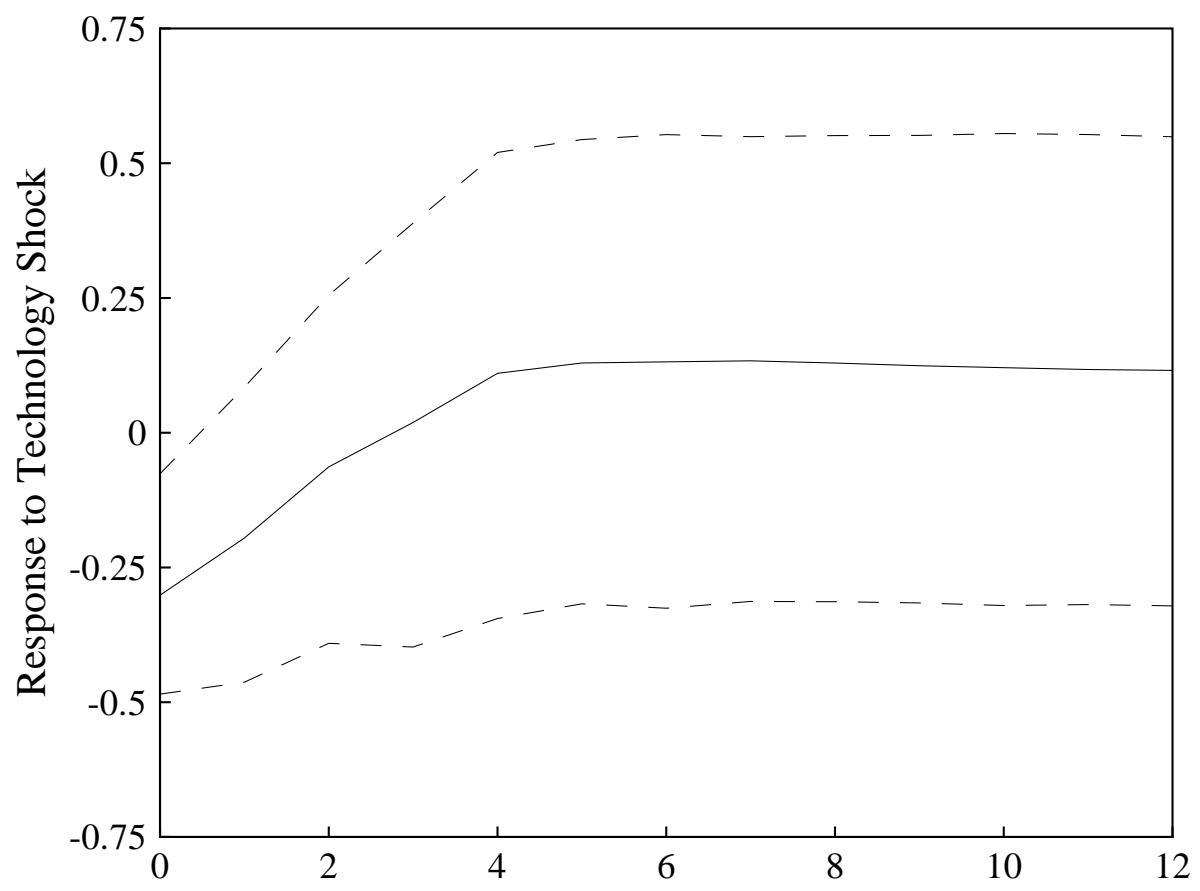

Figure 1. SVAR Impulse Response of U.S. Total Hours to Technology

(Dashed lines mark upper and lower values of the $95 \%$ confidence band for bootstrapped standard errors)

the nonfarm business sector as GR do, but with gross domestic product (GDP) and total hours. ${ }^{2}$ In Figure 1, I show the response of total hours to a one-time, one-percent innovation in technology (that is, a one-percent increase in the first element of $e_{0}$ ). I also plot the 95 percent confidence bands computed using the method described by Runkle (1987). Using the aggregate series for productivity and hours is not a problem for GR, since I reach the same conclusions as they do. In particular, Figure 1 shows that hours fall on impact in response to a rise in technology. In standard $\mathrm{RBC}$ models, hours rise on impact in response.

A second statistic that is emphasized in the literature is the contribution of technology to the variance of logged output and hours, which is computed after these series are filtered with a band-pass filter. With data from the nonfarm business sector, GR find that only 7 percent of output fluctuations and 5 percent of hours fluctuations are due to technology. For my example with GDP and total hours, I find that 14 percent of output fluctuations and 9 percent of hours fluctuations are due to technology. Thus, like GR, I find that the

2 See McGrattan 2004 for data sources. 
SVAR predicts that technology plays a small role in the business cycle.

\subsection{A Standard RBC Model}

I am going to evaluate the SVAR findings using a standard RBC model. In particular, I work with a version of the model in McGrattan (1994) with parameters estimated by maximum likelihood for U.S. data. I simulate many time series from that model, and I apply the SVAR procedure to the artificial data. This exercise allows me to compare the SVAR statistics to their theoretical counterparts. I also determine if the SVAR recovers the technology shocks that I feed into the model.

The model economy is a standard growth model with households, firms, and a government. The representative household with $N_{t}$ members in period $t$ chooses per-capita consumption $c$, per-capita investment $x$, and the labor input $l$ to solve the following maximization problem:

$$
\begin{array}{cc}
\left.\max _{\left\{c_{t}, x_{t}, l_{t}\right\}} E \sum_{t=0}^{\infty} \beta^{t}\left[c_{t}\left(1-l_{t}\right)^{\psi}\right)^{1-\sigma}-1\right] /(1-\sigma) N_{t} \\
\text { subject to } c_{t}+\left(1+\tau_{x t}\right) x_{t}=r_{t} k_{t}+\left(1-\tau_{l t}\right) w_{t} l_{t}+T_{t} \\
N_{t+1} k_{t+1}=\left[(1-\delta) k_{t}+x_{t}\right] N_{t} \\
c_{t}, x_{t} \geq 0 \quad \text { in all states }
\end{array}
$$

taking initial capital $k_{0}$ and processes for the rental rate $r$, wage rate $w$, the tax rates $\tau_{x}$ and $\tau_{l}$, and transfers $T_{t}$ as given. I assume that $N_{t}$ grows at rate $\gamma_{n}$.

The representative firm solves a simple static problem at $t$ :

$$
\max _{\left\{K_{t}, L_{t}\right\}} K_{t}^{\theta}\left(Z_{t} L_{t}\right)^{1-\theta}-r_{t} K_{t}-w_{t} L_{t} .
$$

where $\theta$ is the share of capital in production, capital letters denote economy aggregates, and $Z_{t}$ is the level of technology which varies stochastically around a constant growth trend. In particular, I assume that $Z_{t}=\left(1+\gamma_{z}\right)^{t} z_{t}$ where $\gamma_{z}$ is the trend growth rate and $z_{t}$ is stochastic. Total factor productivity in this economy is $Z_{t}^{1-\theta}$.

The government sets rates of taxes and transfers in such a way that it can finance a stochastic sequence of per-capita purchases $g_{t}$ and satisfy its budget constraint,

$$
N_{t} g_{t}+N_{t} T_{t}=N_{t}\left[\tau_{l t} w_{t} l_{t}+\tau_{x t} x_{t}\right]
$$




\section{Table 1}

\section{Parameters of Vector AR(1) Stochastic Process for the Model ${ }^{\dagger}$}

Estimated Using Maximum Likelihood with Data on Output, Labor, Investment, and Government Consumption

\begin{tabular}{|c|c|c|c|c|c|c|c|c|c|}
\hline \multirow{4}{*}{$P=$} & $-\begin{array}{l}.769 \\
(.0239)\end{array}$ & $\begin{array}{l}.0471 \\
(.0959)\end{array}$ & $\begin{array}{l}.432 \\
(.0756)\end{array}$ & $\left.\begin{array}{l}-.0419 \\
(.0570)\end{array}\right]$ & \multirow{4}{*}{$Q=$} & {$\left[\begin{array}{c}.0108 \\
(.00113)\end{array}\right.$} & 0 & 0 & 0 \\
\hline & $\begin{array}{c}-.0233 \\
(.0601)\end{array}$ & $\begin{array}{l}.994 \\
(.0133)\end{array}$ & $\begin{array}{l}.0417 \\
(.120)\end{array}$ & $\begin{array}{c}-.00452 \\
(.0128)\end{array}$ & & $\begin{array}{c}-.00257 \\
(.00120)\end{array}$ & $\begin{array}{l}.00623 \\
(.00135)\end{array}$ & 0 & 0 \\
\hline & $\begin{array}{l}-.101 \\
(.0186)\end{array}$ & $\begin{array}{l}.0253 \\
(.0445)\end{array}$ & $\begin{array}{l}1.18 \\
(.00780)\end{array}$ & $\begin{array}{l}-.0180 \\
(.0224)\end{array}$ & & $\begin{array}{l}.00371 \\
(.00101)\end{array}$ & $\begin{array}{l}.000888 \\
(.00102)\end{array}$ & $\begin{array}{l}.00196 \\
(.00165)\end{array}$ & 0 \\
\hline & $\begin{array}{l}-.0306 \\
(.0712)\end{array}$ & $\begin{array}{l}.0423 \\
(.0257)\end{array}$ & $\begin{array}{c}-.00160 \\
(.136)\end{array}$ & $\begin{array}{l}.997 \\
(.0212)\end{array}$ & & {$\left[\begin{array}{l}-.00501 \\
(.00214)\end{array}\right.$} & $\begin{array}{l}.00505 \\
(.00266)\end{array}$ & $\begin{array}{l}.0148 \\
(.00102)\end{array}$ & $\begin{array}{c}.00000202 \\
(.0610)\end{array}$ \\
\hline
\end{tabular}

$\dagger$ Numbers in parentheses are standard errors.

each period. In equilibrium, the following conditions must hold:

$$
\begin{aligned}
& N_{t}\left(c_{t}+x_{t}+g_{t}\right)=Y_{t}=K_{t}^{\theta}\left(Z_{t} L_{t}\right)^{1-\theta} \\
& N_{t} k_{t}=K_{t} \\
& N_{t} l_{t}=L_{t} .
\end{aligned}
$$

The model has four exogenous shocks, namely total factor productivity, a tax on labor, a tax on investment, and government spending. The process governing these shocks is

$$
s_{t+1}=P_{0}+P s_{t}+Q \epsilon_{t+1}
$$

where $s_{t}=\left[\log z_{t}, \tau_{l t}, \tau_{x t}, \log g_{t}-t \log \left(1+\gamma_{z}\right)\right]$. I compute maximum likelihood estimates for $P_{0}, P$, and $Q$ using data on U.S. output, investment, hours, and government spending for the period 1959:1-2003:4. ${ }^{3}$ These estimates are reported in Table 1.

3 I fixed parameters of utility and technology as follows: $\psi=2.24, \sigma=1, \beta=.9722, \theta=.35, \delta=.0464$, $\gamma_{n}=1.5 \%$, and $\gamma_{z}=1.6 \%$. These values are standard in the literature. I also restrict measurement errors in observed data to be very small. See McGrattan (2004) for further details. 


\subsection{The Model Predictions}

Given estimates for the parameters, I compute an equilibrium for the model economy which implies decision rules for $c_{t}, x_{t}, l_{t}$, and $k_{t+1}$ in terms of the state variables $k_{t}, z_{t}, \tau_{l t}, \tau_{x t}$, and $g_{t}$ (once I have detrended all variables that grow over time).

I can use these decision rules to compute impulse responses and contributions to the output spectrum for each of the four shocks. Because $P$ and $Q$ are not diagonal, a specification soundly rejected by a likelihood ratio test, estimates of the theoretical impulse responses and the contributions to the spectrum depend on how I decompose $Q Q^{\prime}$ (or, equivalently, how I order $s$ keeping $Q$ lower triangular). For the estimated parameters in Table $1, d \log l_{t} / d \log \epsilon_{z, t}$ is positive for all decompositions, where $\epsilon_{z, t}$ is the first element of $\epsilon_{t}$. In terms of the contributions to the output spectrum, technology shocks are important no matter how I assign covariances. The contribution, averaged across all possible assignments, is over 35 percent. If I compute the contributions for all examples with $z$ first in $s$ and $Q$ lower triangular, I find that the average contribution of technology to the output spectrum is 70 percent. Thus, as most RBC models predict, hours rise in response to a technology shock and technology shocks are important contributors to the business cycle.

Given the empirical findings of the SVAR, GR and others they survey conclude that RBC models such as the one I just described are simply not consistent with U.S. data.

\subsection{The Death Knell for the SVAR Procedure?}

I now describe an obvious check on the SVAR methodology. I act as the data generating process and let the SVAR user be the detective. This is a game I play when I teach students at the University of Minnesota. I give the students "data" for an economy of my own making and they have to tell me what is driving fluctuations in that economy.

With my RBC model, I draw 1000 random sequences of length 180 for the $\epsilon$ vector in (2.5). I use decision functions to compute 1000 sequences for productivity and hours. I then apply the SVAR procedure to each model simulation to get impulse responses. The result is displayed in Figure 2. Figure 2 shows the mean responses (with a solid line). The dashed lines mark the upper and lower value of the interval containing 95 percent of the responses. They are obtained by eliminating the top 2.5 percent and the bottom 2.5 percent for each impulse response coefficient. 


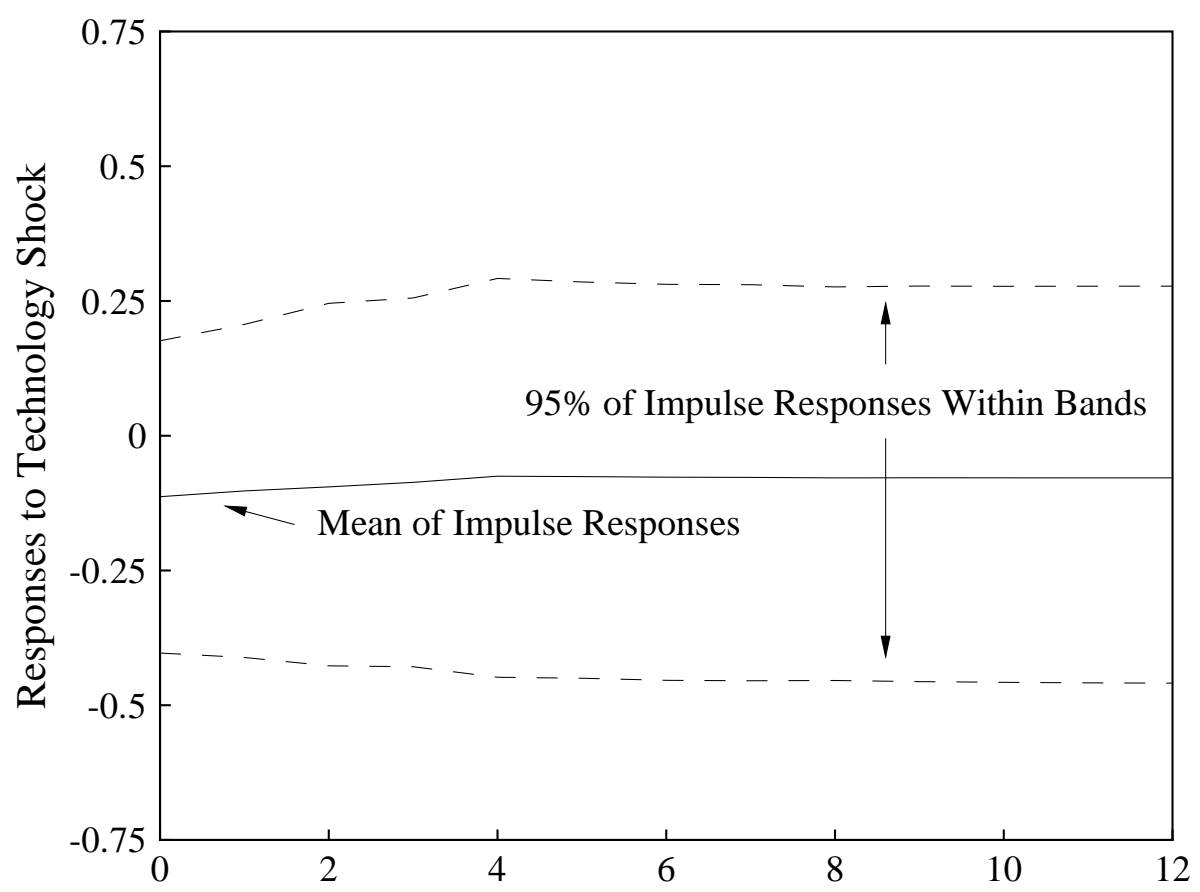

Figure 2. SVAR Impulse Response of Model Hours to Technology

Figure 2 shows that for most of the simulations, and on average, a researcher using the SVAR procedure would infer that hours fall in response to a positive technology shock. This is the same inference I would make for the U.S. data using this procedure. (See Figure 1.) If I compute the contribution of technology to the variance of logged output and hours (after applying a band-pass filter), I find that a researcher using the SVAR procedure would infer that the fractions of the variance of logged output and hours are 26.7 percent and 6 percent, respectively. Recall that when I apply the SVAR to U.S. data the contributions of technology to output and hours fluctuations are 14 percent and 9 percent, respectively. Because hours fall in response to a positive technology shock and because the contribution of technology to the business cycle is smaller than RBC theory predicts, an SVAR user would conclude that the data could not have come from an RBC model. But the data did come from an RBC model.

Figure 2 should not be surprising given the parameters of the model are maximum likelihood estimates for the U.S. data. It simply reflects the fact that my RBC model can produce time series for the key macro aggregates that have similar patterns to those in the U.S. data. In fact I could think of the U.S. data as one draw of time series from 
the model because I can choose the sequence of four shocks in $\epsilon_{t}$ to exactly match the observed sequences for output, investment, labor, and government consumption. Unless the U.S. data were unlikely given my probability model, I should get SVAR results similar to those reported in Figure 1. It turns out that they are not unlikely.

In the exercise leading up to Figure 2, I treated tax rates as unobserved. These tax rates can be interpreted as summarizing all distortions to factors of production. However, one could do the same exercise with measures of a key component of these distortions, namely income taxes on labor and capital. In McGrattan (1994), I use data from the U.S. Internal Revenue Service and the U.S. national accounts to construct estimates for taxes on capital and labor. I estimate the parameters of the model with tax rates observed and show that the model produces time series for key macro aggregates that have similar patterns to those in the U.S. data. A good fit between U.S. data and the model time series implies an empirical impulse response like that in Figure 1 if I apply the SVAR procedure to simulated time series of the model.

What if I compare the technology implied by the SVAR procedure to the log of total factor productivity implied by the model? Technology backed out using the SVAR is the cumulative sum of the first element of $e_{t}$ in (2.2). The log of technology implied by the model is $\log Z_{t}$ in (2.4) computed with U.S. data for $Y, K$, and $L$. In Figure 3, I plot the two series after applying the Hodrick-Prescott filter. The figure shows that the SVAR does not back out the true technology.

In fact, the realization of their technology has very different properties than its theoretical counterpart. It is barely correlated with GDP and negatively correlated with total hours. The correlations with GDP and hours are 0.42 and -0.04 , respectively. The true technology is highly correlated with GDP and positively correlated with total hours. The correlations with GDP and hours are 0.84 and 0.43 , respectively.

\subsection{Why Does the SVAR Get It So Wrong?}

The literature that directly or indirectly critiques the SVAR approach gives us many possible answers to this question. ${ }^{4}$ The problem could be mistaken assumptions about the dimension of the shock vector. It could be mistaken assumptions about the orthogonality

4 See, for example, Sims (1971, 1972), Hansen and Sargent (1991), Lippi and Reichlin (1993), Faust and Leeper (1997), Cooley Dwyer (1998), Erceg et al. (2004), and Uhlig (2004). 


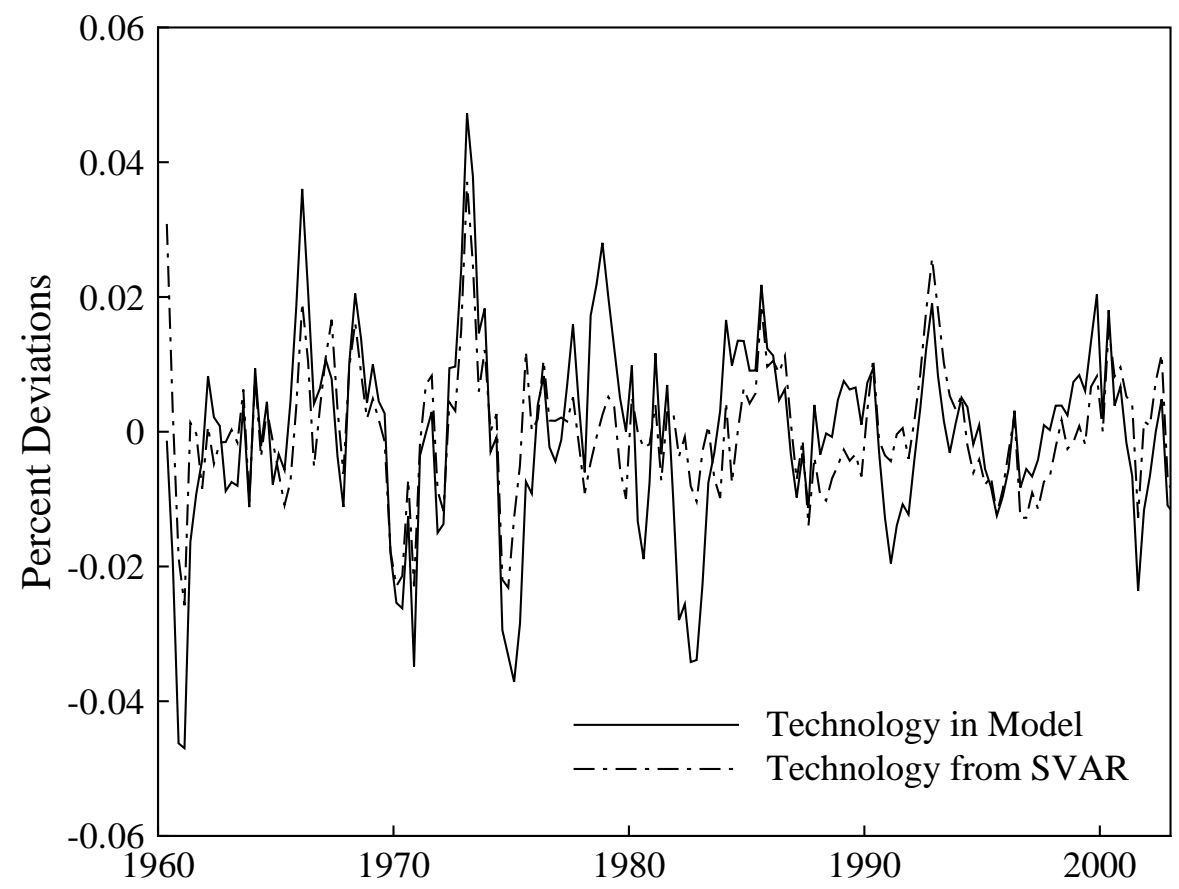

Figure 3. Technology Shocks from the Model and Those Predicted by the SVAR

of the shocks. It could be mistaken assumptions about whether growth trends are deterministic or stochastic. It could be mistaken assumptions about the long-run implications of non-technology shocks. It could be that data samples are too short. It could be that four lags in the VAR are not enough. It could be a more subtle problem like the lack of invertibility of the RBC model's theoretical MA. In fact, for the example above, which is based on a standard RBC model and an SVAR procedure that has been applied many times, the answer is: all of the above.

SVARs are held up as useful tools that reveal "facts" about the data without having to get into the messy details of economic theories. Typically these "facts" are then used to point researchers in the direction of a promising class of models and away from models that are not consistent with them. If the identifying assumptions of the SVAR are relevant for only a tiny subset of models within a class of models, then claims should be made in the context of the tiny subset.

Chari, Kehoe, and McGrattan (2004) extend the analysis I have done here and show that mistaken inferences are large even if my RBC model is restricted to satisfy the key identifying assumptions laid out in Section 2.1. That is, we restrict the model to have only 
two orthogonal shocks: the technology shock $Z_{t}$ and the tax rate $\tau_{l t}$ (or "demand shock"), with a unit root in $Z_{t}$ and an autoregressive process for $\tau_{l t}$. We show that auxiliary assumptions that SVAR researchers make are not innocuous. For the technology-driven SVAR analyzed by GR and many others, an important assumption is the number of lags in the VAR. If capital accumulation is a central component of the model, we show that hundreds of lags are needed to detect the true impulse responses. The sample we have, on the other hand, is only 180 periods long. This is an important finding since the model being studied is the growth model, the workhorse of applied macroeconomic research. Perhaps this finding is the death knell of SVAR analysis.

Chari, Kehoe, and McGrattan (2004) also show that the RBC model of Section 2.2 encompasses the statistical model generated by the SVAR. That is, if the data comes from this RBC model we can account for the prediction of the SVAR that hours fall on impact when there is a positive technology shock. The SVAR model, on the other hand, does not encompass the RBC model since it cannot be used to make predictions about many of the statistics of interest to business cycle researchers, such as the relative variance of investment to output.

Let me summarize what I have learned from these exercises. We should not view the empirical impulse responses from an SVAR as something we want our theoretical impulse responses to reproduce. SVAR users can and should do the same diagnostic checks as Chari, Kehoe, and McGrattan (2004). The analysis has to be done within the context of a theoretical model or a class of theoretical models. Of course, this brings us full circle: once we construct a theoretical model, there is no reason to use an SVAR.

\section{A Triple-Sticky Model vs. U.S. Facts}

The second part of Gali and Rabanal's paper considers life "after RBC models" (which was the original title of the paper). They describe a model that, at least for some parameterizations, is consistent with the VAR evidence laid out in the first part of their paper. This model, which I call the "triple-sticky" model has sticky prices, sticky wages, and habit persistence ("sticky consumption"). They estimate the model and report the contributions of different shocks to aggregate fluctuations. From that, they conclude that demand factors - not technological factors - are key for business cycles. 


\subsection{A Forgotten Lesson From RBC Theory}

Before discussing the triple-sticky business-cycle model, I should review an important lesson from the RBC literature. GR's triple-sticky model includes lots of frictions. Unfortunately, it excludes the key component in modern business cycle models: investment.

One important lesson from previous business-cycle research is that the main impact of technology on the cycle is through investment, not through hours. By leaving out investment, GR are minimizing the role that technology would have. For this reason, I bring investment back in.

\subsection{A Triple-Sticky Model with Investment}

The model I work with has many of the same elements as those in Chari, Kehoe, and McGrattan $(2000,2002)$ and McGrattan (1999). In order to compare my results to those of GR, I also allow for habit persistence in consumer preferences and preference shocks.

\subsection{Effects of Monetary Shocks}

One of the main results in GR is that demand shocks are the main force for the business cycle. Given the choice of model used by GR, it is natural to ask if money is an important demand shock. Nominal rigidities let money shocks have real effects, and habit persistence extends the effects.

To investigate the role of money, I compare time series from data (after detrending or demeaning) with time series from my triple-sticky model. I set parameters to be consistent with GR's model wherever possible and otherwise use standard estimates from the business cycle literature. In Figures 4 and 5, I show simulations of the model hit only by shocks to the Taylor rule (A.8). For the sequence of shocks, I use innovations from Clarida, Gali, and Gertler's (2000) estimated Taylor rule. The figures confirm the finding of GR that monetary shocks in these models play only a small role. Even if I do not add habit persistence, the model predictions are far too smooth relative to the fluctuations in the data.

If I include plausible shocks to technology and government spending, the match between actual and predicted improves slightly. ${ }^{5}$ But inflation in the model is still much

5 This is also demonstrated in McGrattan (1999). 


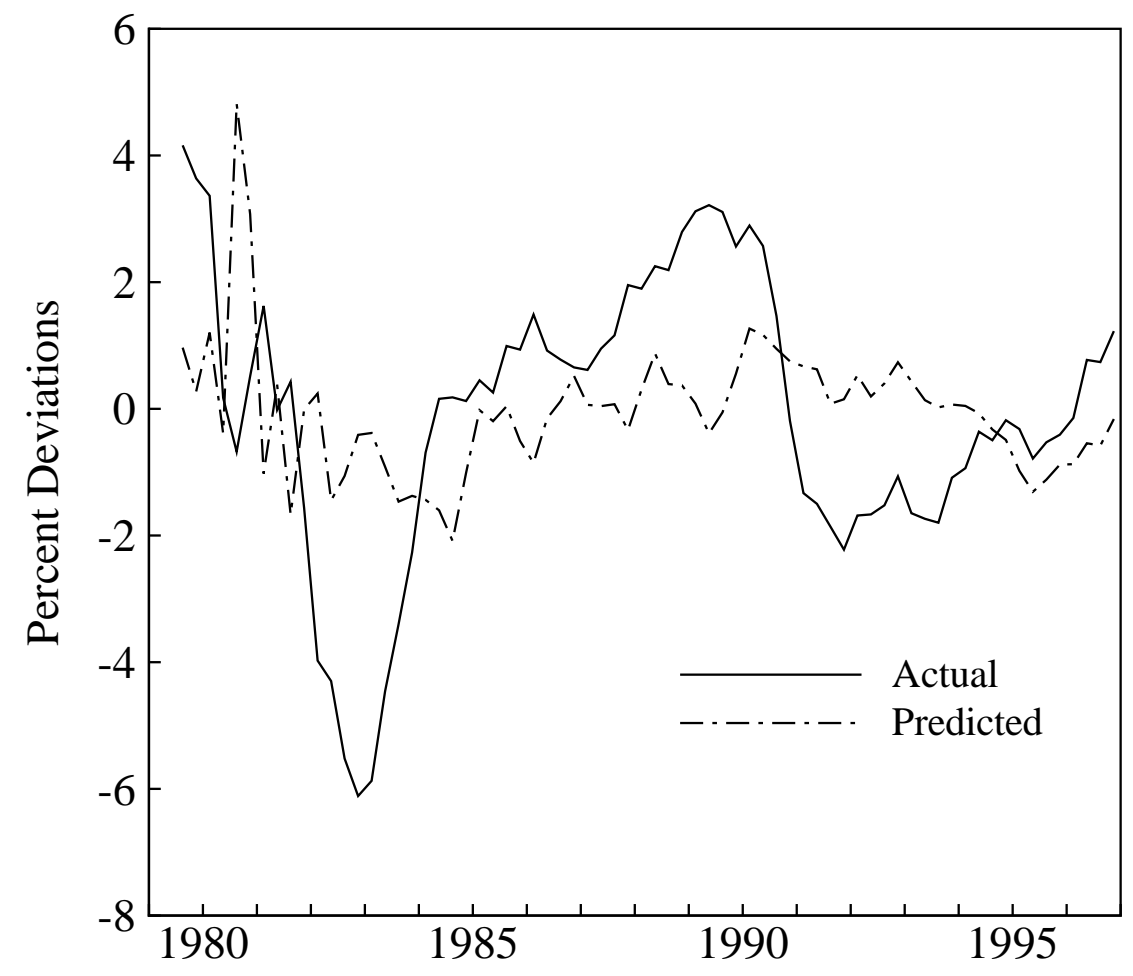

Figure 4. GDP Relative to Trend

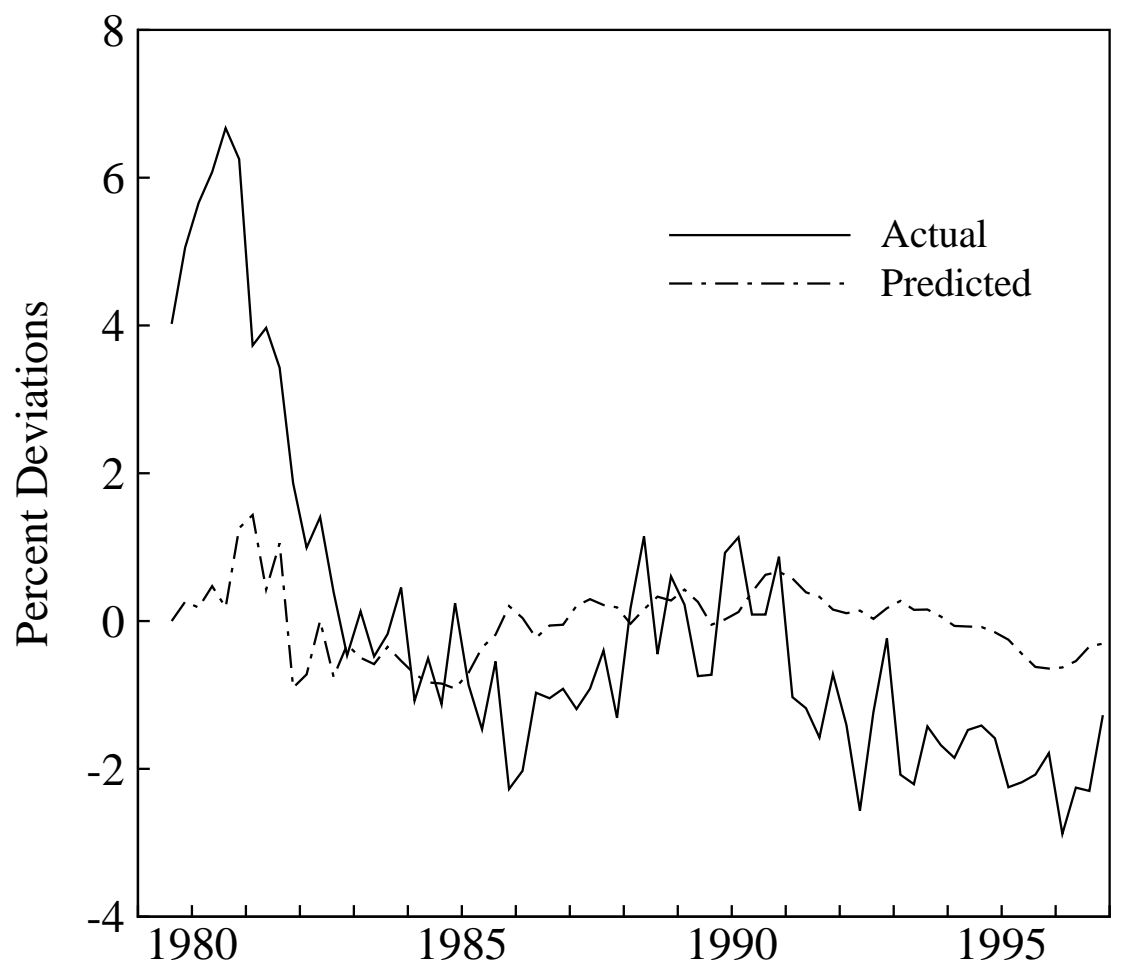

Figure 5. Inflation Relative to its Mean 
smoother than in the data. Thus, any missing "demand" shocks must fill in the gap between actual and predicted inflation, which was particularly large in the 1970s and early 1980s.

\subsection{What are the Demand Shocks?}

If it is not money, government spending, or technology, what drives business cycle fluctuations? The answers for GR are preference shocks and shocks to the degree of monopoly power. For GR, these unobserved "demand" shocks account for 80 percent of the variance in hours, 72 percent of the variance in output, and 65 percent of the variance in inflation. As I find with my triple-sticky model, observed factors account for a very small fraction of the business cycle.

This is reminiscent of the finding of Rotemberg and Woodford (1997). To generate U.S.-like business cycles, Rotemberg and Woodford need large and variable shocks to preferences and to a variable called aggregate demand appearing in the resource constraint. In the appendix to their paper they report that standard deviations of the shocks to preferences are 13.7 percent. This is large relative to the standard deviation of logged output which is only 2.1 percent.

The fluctuations of aggregate demand shocks, which are shocks to the resource constraint and enter additively with consumption, are even larger. The standard deviation is 29.5 percent, 14 times that of logged output. Furthermore, plotting the aggregate demand shocks yields a picture that looks a lot like inflation. This is not surprising since there is a large gap between actual and predicted inflation without the unobserved shocks.

In summary, given my calculations and those of Rotemberg and Woodford (1997), I was not surprised that GR find they need a large role for unobserved preference shocks and shocks to the degree of monopoly power. I am not convinced that this is progress. It seems to me that we are simply replacing an old black box ("technology shocks") with a new black box ("demand shocks").

\section{Conclusions}

GR have written a thought-provoking paper claiming that RBC models are not consistent with U.S. data. I have shown that the SVAR methodology they use fails a simple diagnostic 
test. When given data from an RBC model, the SVAR procedure tells us that the data could not have come from an RBC model.

I have analyzed a version of GR's triple-sticky model, extending it to include investment. Like GR, I find that the model does a poor job generating U.S.-like business cycles with only technology and monetary shocks. The fit of GR's model to U.S. data, therefore, requires the inclusion of large unobserved shocks to preferences and to the degree of monopoly power.

Finally, I should note that the RBC literature has moved far beyond Kydland and Prescott (1982). Current research is modeling sources of variation in total factor productivity in large part as arising from variations in government policies, not from variations in the stock of blueprints. ${ }^{6}$ This work came about partly in response to claims that total factor productivity in Kydland and Prescott (1982) was an exogenous black box. I encourage GR to consider these recent studies before shifting the black box from technology to demand.

6 See for example, Parente and Prescott (2000), Lagos (2003), and Schmitz (2004). 


\section{A. Appendix}

This appendix provides details of the triple-sticky model I simulate. For details on computation, see McGrattan (2004).

In each period $t$, the model economy experiences one of finitely many events $s_{t}$. I denote by $s^{t}=\left(s_{0}, \ldots, s_{t}\right)$ the history of events up through and including period $t$. The probability, as of period zero, of any particular history $s^{t}$ is $\pi\left(s^{t}\right)$. The initial realization $s_{0}$ is given.

There are producers of final goods and intermediate goods. Final goods producers behave competitively and solve a static profit-maximization problem. In each period producers choose inputs $y(i)$ for $i \in[0,1]$ and output $y$ to maximize profits:

$$
\max P y-\int_{0}^{1} P(i) y(i) d i \quad \text { subject to } y=\left(\int_{0}^{1} y(i)^{\theta} d i\right)^{\frac{1}{\theta}}
$$

where $y$ is the final good, $P$ is the price of the final good, $y(i)$ are intermediate goods, and $P(i)$ are the prices of the intermediate goods. The demand for intermediate goods, which I use later, is given by $y(i)=[P / P(i)]^{\frac{1}{1-\theta}} y$.

Consider next the problem faced by intermediate goods producers. Intermediate goods producers are monopolistically competitive. They set prices for their goods, but they must hold them fixed for $N$ periods. I assume that price-setting is done in a staggered fashion so that $1 / N$ of the firms are setting in a particular period. I compute a symmetric equilibrium so I assume that all firms $i \in[0,1 / N]$ behave the same way, all firms $i \in[1 / N, 2 / N]$ behave the same way, and so on.

More specifically, the problem solved by the intermediate goods producers setting prices is to choose sequences of prices $P(i)$, capital stocks $k(i)$, investments $x(i)$, and labor inputs $l(i, j), j=1, \ldots, \mathcal{N}$ to maximize

$$
\sum_{\tau=0}^{\infty} \sum_{s^{\tau}} \tilde{Q}\left(s^{\tau}\right)\left[P\left(i, s^{\tau}\right) y\left(i, s^{\tau}\right)-\int W\left(j, s^{\tau-1}\right) l\left(i, j, s^{\tau}\right) d j-P\left(s^{\tau}\right) x\left(i, s^{\tau}\right)\right]
$$

subject to the input demand, the production technology:

$$
y\left(i, s^{t}\right)=k\left(i, s^{t-1}\right)^{\alpha}\left(A\left(s^{t}\right) L^{d}\left(i, s^{t}\right)\right)^{1-\alpha}
$$

the constraint on labor

$$
L^{d}\left(i, s^{t}\right) \leq\left[\int l\left(i, j, s^{t}\right)^{v} d j\right]^{\frac{1}{v}}
$$


the law of motion for capital used in producing good $i$

$$
k\left(i, s^{t}\right)=(1-\delta) k\left(i, s^{t-1}\right)+x\left(i, s^{t}\right)-\phi\left(\frac{x\left(i, s^{t}\right)}{k\left(i, s^{t-1}\right)}\right) k\left(i, s^{t-1}\right)
$$

and the following constraints on prices:

$$
\begin{aligned}
P\left(i, s^{t-1}\right) & =P\left(i, s^{t}\right)=\ldots P\left(i, s^{t+N-1}\right) \\
P\left(i, s^{t+N}\right) & =P\left(i, s^{t+N+1}\right)=\ldots P\left(i, s^{t+2 N-1}\right)
\end{aligned}
$$

and so on, where $\tilde{Q}\left(s^{\tau}\right)$ is the $\tau$ th period Arrow-Debreu price (that is, a product of the one-period $Q\left(s^{t} \mid s^{t-1}\right)$ 's).

Consider next the problem faced by consumers of final goods who are wage-setters. One can think of the economy organized into a continuum of unions indexed by $j$. Each union $j$ consists of all the consumers in the economy with labor of type $j$. This union realizes that it faces a downward sloping demand curve for its type of labor. It sets nominal wages for $\mathcal{N}$ periods at $t, t+\mathcal{N}, t+2 \mathcal{N}$, and so on. Thus, it faces constraints

$$
\begin{aligned}
W\left(j, s^{t-1}\right) & =W\left(j, s^{t}\right)=\ldots=W\left(j, s^{t+\mathcal{N}-1}\right) \\
W\left(j, s^{t+\mathcal{N}}\right) & =W\left(j, s^{t+\mathcal{N}+1}\right)=\ldots=W\left(j, s^{t+2 \mathcal{N}-1}\right)
\end{aligned}
$$

and so on in addition to the ones I describe below.

The problem solved by a consumer of type $j$ is to maximize utility:

$$
\max \sum_{t=0}^{\infty} \sum_{s^{t}} \beta^{t} \pi\left(s^{t}\right) U\left(c\left(j, s^{t}\right), c\left(j, s^{t-1}\right), L^{s}\left(j, s^{t}\right), M^{d}\left(j, s^{t}\right) / P\left(s^{t}\right) ; \varphi_{t}\right),
$$

which allows for habit persistence and preference shocks $(\varphi)$, subject to the sequence of budget constraints, the definition of labor supply, and the labor demands of the firms:

$$
\begin{aligned}
P\left(s^{t}\right) c\left(j, s^{t}\right)+M^{d}\left(j, s^{t}\right)+\sum_{s_{t+1}} Q\left(s^{t+1} \mid s^{t}\right) B\left(j, s^{t+1}\right) & \\
& \leq W\left(j, s^{t-1}\right) L^{s}\left(j, s^{t}\right)+M^{d}\left(j, s^{t-1}\right)+B\left(j, s^{t}\right)+\Pi\left(s^{t}\right)+T\left(s^{t}\right) \\
L^{s}\left(j, s^{t}\right) & =\int l\left(i, j, s^{t}\right) d i \\
l\left(i, j, s^{t}\right) & =\left(\frac{\bar{W}\left(s^{t}\right)}{W\left(j, s^{t-1}\right)}\right)^{\frac{1}{1-v}} L^{d}\left(i, s^{t}\right), \text { for all } i .
\end{aligned}
$$


There are also borrowing constraints $B\left(s^{t+1}\right) \geq-P\left(s^{t}\right) \bar{b}$. $M$ and $B$ are consumers' holdings of money and contingent claims, $Q$ is the price of the claims, $W\left(j, s^{t-1}\right)$ is the nominal wage chosen by one cohort of consumers, $\Pi$ are profits, and $T$ are government transfers. The consumer agrees to supply whatever is demanded at that wage chosen.

The government in this world behaves in such a way that the nominal interest rate set by the Federal Reserve is given by

$$
\begin{aligned}
r\left(s^{t}\right)=a^{\prime} & r\left(s^{t-1}\right), r\left(s^{t-2}\right), r\left(s^{t-3}\right), E_{t} \log \left(P\left(s^{t+1}\right) / P\left(s^{t}\right)\right), \\
& \log \left(P\left(s^{t}\right) / P\left(s^{t-1}\right)\right), \log \left(P\left(s^{t-1}\right) / P\left(s^{t-2}\right)\right), \log \left(P\left(s^{t-2}\right) / P\left(s^{t-3}\right)\right), \\
& \left.\log y\left(s^{t}\right), \log y\left(s^{t-1}\right), \log y\left(s^{t-2}\right)\right]+ \text { constant }+\epsilon_{r, t} .
\end{aligned}
$$

The government also spends $g\left(s^{t}\right)$, and thus, the economy-wide resource constraint is

$$
y\left(s^{t}\right)=\int_{0}^{1} c\left(j, s^{t}\right) d j+\int_{0}^{1} x\left(i, s^{t}\right) d i+g\left(s^{t}\right) .
$$

For the simulations in Figure 4 and 5 , I set $N=4, \mathcal{N}=2, U\left(c, c_{-1}, l, m\right)=\log (c-$ $\left..42 c_{-1}\right)-l^{1.8} / 1.8+.0076 m^{-1.56} /(-1.56), \theta=.9, v=.87, \alpha=1 / 3, \beta=.97^{1 / 4}, E g\left(s^{t}\right)=.6$, $\delta=1-.92^{1 / 4}$, and $\phi(x / k)=10(x / k-\delta)^{2}$. The Taylor rule in $(A .8)$ is that estimated by Clarida, Gali, and Gertler (2000). 


\section{References}

Blanchard, Olivier J. and Danny Quah (1989), "The Dynamic Effects of Aggregate Demand and Supply Disturbances," American Economic Review, 79: 655-673.

Chari, V. V., Patrick J. Kehoe, and Ellen R. McGrattan (2000), "Sticky price models of the business cycle: Can the contract multiplier solve the persistence problem?" Econometrica, 68: 1151-1179.

Chari, V. V., Patrick J. Kehoe, and Ellen R. McGrattan (2002), "Can Sticky Price Models Generate Volatile and Persistent Real Exchange Rates?" Review of Economic Studies, 69: $533-563$.

Chari, Kehoe, and McGrattan (2004), "Are Structural VARs Useful Guides for Developing Business Cycle Theories?" Federal Reserve Bank of Minneapolis, Working Paper \#631.

Clarida, Richard, Jordi Gali, and Mark Gertler (2000), "Monetary Policy Rules and Macroeconomic Stability: Evidence and Some Theory," Quarterly Journal of Economics, 115: 147-180.

Cooley, Thomas F. and Mark Dwyer (1998), "Business Cycle Analysis Without Much Theory: A Look at Structural VARs," Journal of Econometrics, 83: 57-88.

Erceg, Christopher, Luca Guerrieri, and Christopher Gust (2004), "Can Long-run Restrictions Identify Technology Shocks?" Board of Governors of the Federal Reserve System, International Finance Discussion Paper 792.

Faust, Jon and Eric Leeper (1997), "When Do Long-Run Identifying Restrictions Give Reliable Results?" Journal of Business and Economic Statistics, 15: 345-353.

Francis, Neville and Valerie A. Ramey (2002), "Is the Technology-Driven Real Business Cycle Hypothesis Dead?" NBER Working Paper \#8726.

Hansen, Lars Peter and Thomas J. Sargent (1991), "Two Difficulties in Interpreting Vector Autoregressions," in Rational Expectations Econometrics, Underground Classics in Economics (Oxford: Westview Press), 77-119.

Kydland, Finn E. and Edward C. Prescott (1982), "Time to Build and Aggregate Fluctuations," Econometrica 50: 1345-70.

Lagos, Ricardo (2003), "A Model of TFP," Federal Reserve Bank of Minneapolis, Mimeo.

Lippi, Marco and Lucrezia Reichlin (1993), "The Dynamic Effects of Aggregate Demand and Supply Disturbances: Comment," American Economic Review, 83: 644-652.

McGrattan, Ellen R. (1994), "The Macroeconomic Effects of Distortionary Taxation," Journal of Monetary Economics, 33: 573-601.

McGrattan, Ellen R. (1999), "Predicting the Effects of Federal Reserve Policy in a Sticky Price Model: An Analytical Approach," Federal Reserve Bank of Minneapolis, Working 
Paper \#598.

McGrattan, Ellen R. (2004), "Technical Appendix: Comment on Gali and Rabanal," Federal Reserve Bank of Minneapolis, Mimeo.

Parente, Stephen L. and Edward C. Prescott (2000), Barriers to Riches, (Cambridge, MA: MIT Press).

Rotemberg, Julio J. and Michael Woodford (1997), "An Optimization-Based Econometric Framework for the Evaluation of Monetary Policy," NBER Macroeconomics Annual, (Cambridge, MA: MIT Press), 297-346.

Runkle, David E. (1987), "Vector Autoregressions and Reality," Journal of Business and Economic Statistics, 5: 437-442.

Schmitz, James A., Jr. (2004), "What Determines Labor Productivity? Lessons From the Dramatic Recovery of the U.S. and Canadian Iron-Ore Industries Since Their Early 1980s Crisis," Federal Reserve Bank of Minneapolis, Staff Report 286.

Sims, Christopher (1971), "Distributed Lag Estimation When the Parameter Space is Explicitly Infinite-Dimensional," Annals of Mathematical Statistics, 42: 1622-1636.

Sims, Christopher (1972), "The Role of Approximate Prior Restrictions in Distributed Lag Estimation," Journal of the American Statistical Association, 67: 169-175.

Uhlig, Harald (2004), "What Are the Effects of Monetary Policy on Output? Results from an Agnostic Identification Procedure." Humbolt University, Mimeo. 